\title{
Preparation and Nonlinear Optical Properties of Novel Polyesters with Enhanced Thermal Stability of Second Harmonic Generation
}

\author{
Jin-Hyang Kim, Dong-Seon Won, and Ju-Yeon Lee* \\ Institute of Functional Materials, Department of Chemistry, Inje Cniversitv, Gimhat 621-749, Korea \\ E-mail: chemlininjeackr \\ Recerved September 3, 2007
}

\begin{abstract}
2.5-Di-(2'-hydroxyethoxy')-4'-nitrostilbene (3) was prepared and polycondensed with terephthaloyl chloride. adipoyl chloride and sebacoyl chloride to yield novel T-type polyesters (4-6) containing the NLOchromophores dioxynitrostilbenyl groups. which constituted parts of the poly mer backbones. Poly mers 4-6 are soluble in common organic solvents such as acetone and N.N-dimethylformamide. They showed thennal stability up to $260{ }^{\circ} \mathrm{C}$ in thermogravimetric analysis with glass-transition temperatures obtained from differential scanning calorimetry in the range $90-95^{\circ} \mathrm{C}$. The second hamnonic generation (SHG) coefficients $\left(d_{33}\right)$ of poled polymer films at the $1064 \mathrm{~nm}$ fundamental wavelength were around $1.42 \times 10^{-9}$ esu. The dipole alignment exhibited high thermal stability up to $5^{\circ} \mathrm{C}$ higher than glass-transition temperature $\left(T_{\mathrm{g}}^{\circ}\right)$. and there was no SHG decay below $100^{\circ} \mathrm{C}$ due to the partial main-chain character of polymer structure. which is acceptable for NLO device applications.
\end{abstract}

Key Words : Nonlinear optics. Polyester. Thermal stability. Second harmonic generation. Relaxation of dipole alignment

\section{Introduction}

A lot of efforts have been directed to the synthesis of nonlinear optical (NLO) materials over the past decade because of their potential applications in the field of electrooptic device applications. The organic materials seem to be superior because of their higher nonlinear optical activity and faster response time than the inorganic ones. Among the organic materials the NLO polymers are receiving great attention. mainly because they offer many advantages such as mechanical endurance. light weight chemical resistance. and good processability to form optical devices. ${ }^{1-3}$ A potential NLO polymer must contain highly polarizable conjugated dipolar electronic sy'stems and they have to be mechanically very strong and thermally stable with high glass-transition temperature $\left(I_{g}\right)$. In the developments of NLO polymers for electro-optic device applications. stabilization of electrically induced dipole alignment is an important consideration. Two approaches to minimize the randomization have been proposed. One is to use crosslinked sy'stem ${ }^{4-7}$ and the other is to utilize high $T_{g}$ polymers such as polyimides. ${ }^{8}$ Various polyesters with the NLOchromophores in the main chain" or in side chain ${ }^{10.12}$ were prepared and investigated. Main-chain NLO polymers have good thermal stability of dipole alignments. but they often do not dissolve in organic solvents. and their intractability make them unusable to fabricate stable noncentrosymmetric films. Side-chain NLO polymer systems have the advantages such as good solubility. homogeneity and high loading level of NLO chromophore but they often suffer from poor stability of dipole alignments at high temperatures. Recently we have prepared novel NLO polyesters ${ }^{13-15}$ with enhanced thermal stability of dipole alignment by modification of polymer structure.

In this work we prepared novel polyesters containing 2.5dioxynitrostilbenyl groups as NLO-chromophores. We selected the latter because they have a large dipole moment and are rather easy' to sy'nthesize. Furthermore. 2.5-dioxynitrostilbenyl groups constitute novel T-type NLO polyesters (Fig. lc). and these T-type NLO polyesters have not been reported in the literature. Thus. we synthesized a new type of NLO polyester. in which the pendant NLO chromophores are parts of the polymer backbones. These mid-type NLO polymers are expected to have the advantages of both mainchain and side-chain NLO polymers: stabilization of dipole alignment and good solubility: After confirming the structure of the resulting polymers we investigated their properties such as solubility. $T_{\mathrm{g}}$, themal stability. surface morpho-

(a)

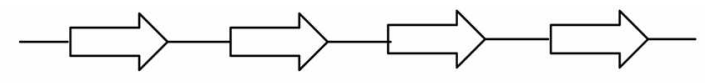

(b)

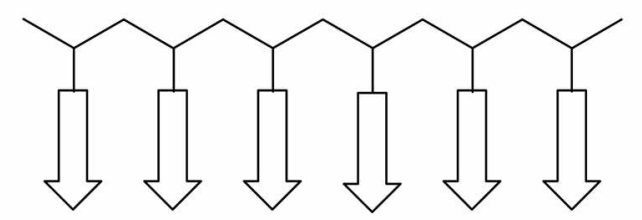

(c)

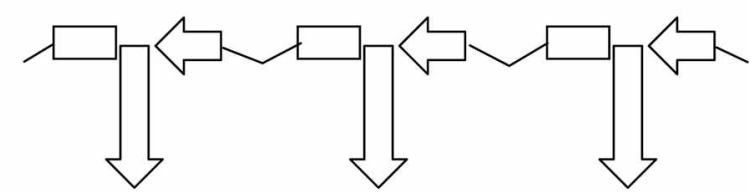

Figure 1. (a) Main-chain NLO polymers, (b) side-chain NLO polymers, and (c) T-type NLO polymers. 


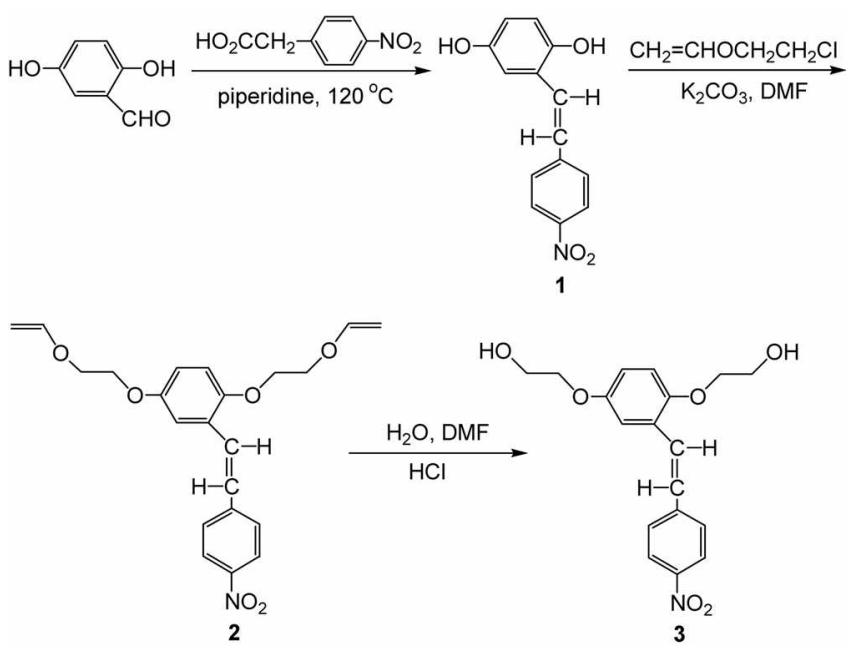

Scheme 1. Synthetic scheme and structure of compound 3.

logy of polymer films, second harmonic generation (SHG) activity and relasation of dipole alignment.

\section{Results and Discussion}

Synthesis and Characterization of Polymers 4-6. 2.5Dihydroxyethoxy-4'-nitrostilbene (1) was prepared by the condensation of 4-nitrophenylacetic acid with 2.5-dihydroxybenzaldehyde according to a literature procedure ${ }^{16}$ Compound 1 was reacted with 2-chloroethyl vinyl ether to yield 2.5-di-(2-yinyloxyethoxy)-4'-nitrostilbene (2). Compound 2 was hydrolyzed to yield acetaldehyde and 2.5 -di(2'-lydroxyethoxy)-4'-nitrostilbene (3). The synthetic route for compound 3 is presented in Scheme 1. The chemical structure of the compounds was identified by ${ }^{1} \mathrm{H}$ NMR (Fig. $2)$, IR spectra. and elemental analysis. All the analytical data confirmed the expected chemical structure. Diol 3 was condensed with terephthaloyl chloride. adipoyl chloride. and sebacoyl chloride in a dry DMF solvent to yield T-type polyesters 4-6 containing the NLO-chromophore 3.4-dioxynitrostilbenyl group (Scheme 2). Polymerization results are summarized in Table 1 . The polymerization yield was $90-$ $95 \%$. The chemical structures of the resulting polymers were confimed by ${ }^{1} \mathrm{H}$ NMR. IR spectra. and elemental analysis. Elemental analysis results fit the polymer structures. ${ }^{1} \mathrm{H}$ NMR spectra of the polymers showed a signal broadening due to polymerization. but the chemical shifts are consistent with the proposed polymer structures. as shown in Figure 2. The signal at $2.05-2.36 \mathrm{ppm}$ assigned to the $\alpha$-proton indicates the formation of ester linkage. The IR spectra of the same polymer samples also show a strong carbonyl peak near $1722-1728 \mathrm{~cm}^{-1}$ indicating the presence of ester bond. For polymers 5 and 6 . the carbonyl absorptions appear at $1728 \mathrm{~cm}^{-1}$, while the carbonyl absorotion in polymer + appears at $1722 \mathrm{~cm}^{-1}$ due to conjugation with aromatic ring. The strong absorptions at 1572.1520 and $1350 \mathrm{~cm}^{-1}$ due to trans double bond and nitro group indicates the presence of stilbene unit. These results are consistent with the proposed structures. indicating that the NLO-chromophore remained intact during the polymerization. The molecular weights were determined by GPC using polystyrene as the standard and THF as an eluent. The number average molecular weight $\left(M_{n}\right)$ of the polymers was deternined to be 16600 $\left(M_{\mathrm{w}} / M_{\mathrm{n}}=1.98\right)$ for polymer 5 . Polydispersities were in the range of 1.79-2.12. The structural feature of these polymers is that they have pendant NLO clromophores. which are parts of the polymer main chains. Thus the resulting polymers (+-6) are mid type of side chain- and main chain NLO polymers. and are expected to have both of their merits. The polymers t-6 were soluble in common solvents such as acetone. DMF, and DMSO, but were not soluble in methanol and diethyl ether. Polymers 4-6 isolated from methanol were yellow colored amorphous materials. The inherent viscosities were in the range of $0.30-0.35 \mathrm{dL} / \mathrm{g}$. Polymers $\mathbf{t - 6}$ showed strong absorption near $375 \mathrm{~nm}$ by the NLOchromophore dioxynitrostilbenyl group. We now have well defined polyesters (4-6) and investigate their properties.

Thermal Properties of the Polymers. The thermal behavior of the polymers were investigated by thermogravimetric analy sis (TGA) and differential scanning calorimeter (DSC) to determine the thermal degradation patten and glass transition temperature $\left(I_{\mathrm{g}}\right)$. The results are summarized in Table 2. In Figure 2. TGA thermograms of the polymers 4-6 are presented. Polymer 4 showed a thermal stability up to $300{ }^{\circ} \mathrm{C}$ from the TGA thermogram. but polymers 5-6 exhibited lower thermal stability than polymer $t$. as shown in Figure 2. Glass transition temperature $\left(l_{\xi}\right)$ values of the polymers 4-6 measured by DSC were in the range $90-95^{\circ} \mathrm{C}$. These $1_{\xi}$ values are higher than those of the polyesters containing 2,3-dioxynitrostilbenyl group. ${ }^{15}$ The TGA and DSC studies showed that the decomposition temperature of the polyesters 4-6 was higher than the corresponding $1 \%$. This indicates that high-temperature poling for a short term is feasible without damaging the NLO chromophore.

Nonlinear Optical Properties of the Polymers. The NLO properties of polymers were studied by the SHG method. To induce noncentrosymmetric polar order. the spin-coated polymer films were corona-poled. As the temperature was raised to $5-10^{\circ} \mathrm{C}$ higher than $T_{\mathrm{g}} .6 .5 \mathrm{kV}$ of corona voltage was applied and kept at that temperature for $30 \mathrm{~min}$. The UV-Vis absorption spectra of the polymer $\mathbf{5}$ before and after poling are presented in Figure 3. After electric poling. the dipole moments of the NLO-chromophores were aligned and the UV-Vis spectrum of polymer 5 exhibited a slight blue shift and a decrease in absorption due to birefringence. From the absorbance change the order parameter of the poled film could be estimated. which is related to the poling efficiency. The estimated order parameter value $\Phi$ was equal to 0.18 for polymer $5\left(\Phi=1-A_{1} /\right.$ $A_{i,}$, where $A_{i j}$ and $A_{l}$ are the absorbances of the polymer film before and after poling). For the purpose of investigating surface morphology of polymer films. domain structures of NLO-chromophores for the thin-film were obtained using atomic force microscopy (AFM). Figure 4 shows AFM scans of the spin-coated film before and after poling for polymer 5. AFM images show that the surface of the film 

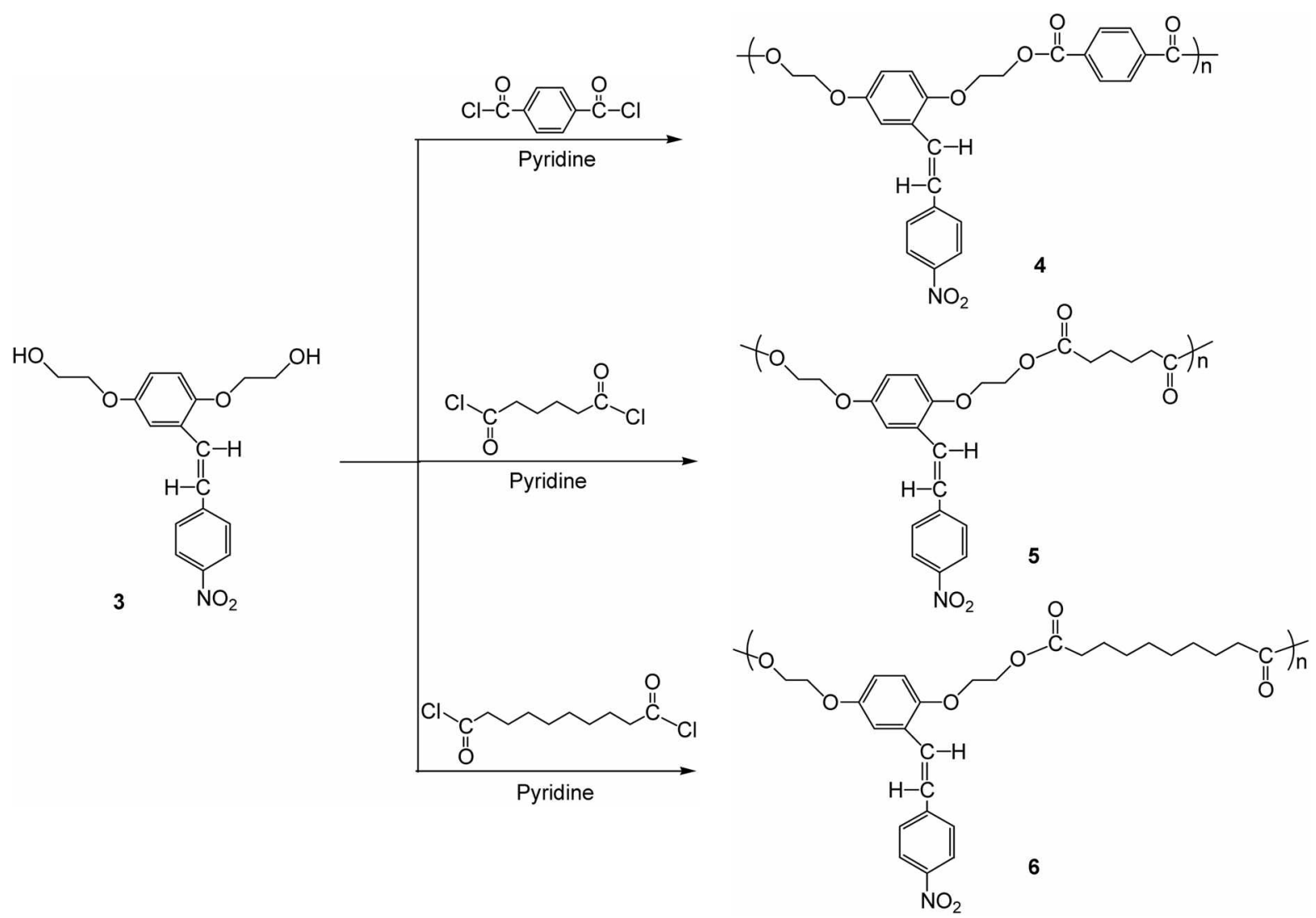

Scheme 2. Synthetic scheme and structures of polymers $\mathbf{4 - 6}$.

Table 1. Polymerization of 3 with TPC, APC and SCC in Pyridine

\begin{tabular}{|c|c|c|c|c|c|c|c|}
\hline $\begin{array}{l}\text { Mono- } \\
\text { mer }{ }^{d-d t}\end{array}$ & $\begin{array}{c}\text { Monomet } \\
\text { Soventt } \\
\text { (mol/L) }\end{array}$ & $\begin{array}{l}\text { Liol } 3 \text { to } \\
\mathrm{R}(\mathrm{COCl})= \\
(\mathrm{mol} / \mathrm{mol})\end{array}$ & $\begin{array}{l}\text { Time } \\
\text { (h) }\end{array}$ & $\begin{array}{l}\text { Yield } \\
(\%)\end{array}$ & $\begin{array}{c}\eta_{\mathrm{nhh}}{ }^{\mathrm{e}} \\
(\mathrm{dL} / \mathrm{g})\end{array}$ & $M_{i i}^{f}$ & $M f_{w}^{f}$ \\
\hline TPC & 67 & 1.0 & 10 & 92 & 0.30 & 15800 & 30600 \\
\hline TPC & 0.80 & 1.0 & 12 & 93 & 0.32 & 16300 & 32500 \\
\hline APC & 0.67 & 1.0 & 10 & 90 & 0.30 & 16600 & 32800 \\
\hline $\mathrm{APC}$ & 0.80 & 1.0 & 12 & 92 & 0.31 & 16500 & 29600 \\
\hline $3, \mathrm{SCC}$ & 0.67 & 1.0 & 10 & 92 & 0.32 & 15200 & 31100 \\
\hline $3, \mathrm{SCC}$ & 0.80 & 1.0 & 12 & 95 & 0.35 & 17400 & 36900 \\
\hline
\end{tabular}

"3 $=2,5$-Di-(2'-hydroxyethoxy) $)$-4-nitrostilbene. "'TPC $=$ Terephthaloyl chloride. "APC = Adipoyl chloride. "SCC = Sebacovl chloride. "Inherent viscosity of polvmer $\left(0.5 \mathrm{~g} d \mathrm{dL}\right.$ in DMSO at $\left.25^{\circ} \mathrm{C}\right)$. Measured by GPC in THF using polystyrene standard.

sample is extremely flat and smooth. However. this good quality film was dramatically changed after poling. resulting in numerous hills and valleys in the surface structure. which means that the NLO-chromophores are aligned the poling direction (see Fig. 4). The refractive index of the sample was measured by the optical transmission technique. ${ }^{17}$ The transmittance of thin film includes information on the thickness. refractive index and extinction coefficient of that. So we could determine those parameters by analyzing the transmittance. SHG measurements were performed at a fundamental wavelength of $1064 \mathrm{~mm}$ using a mode locked NdYAG laser. In order to determine the microscopic secondorder susceptibility of the poly'mer. the angular SHG depend-
Table 2. Thermal Properties of Polymers 4-6

\begin{tabular}{|c|c|c|c|c|c|}
\hline \multirow[b]{2}{*}{ Polymer } & \multirow[b]{2}{*}{ 7! ${ }^{\circ} \mathrm{C}$} & \multicolumn{3}{|c|}{ Degradation temp, ${ }^{\circ} \mathrm{C}$} & \multirow{2}{*}{$\begin{array}{c}\text { Residue } \\
\text { at } 800^{\circ} \mathrm{C} \text {. } \\
\text { wt } \%\end{array}$} \\
\hline & & $\begin{array}{c}5 \text { at } \%- \\
\operatorname{loss}\end{array}$ & $\begin{array}{c}20 \mathrm{w} \% \mathrm{~m} \\
\text { loss }\end{array}$ & $\begin{array}{c}40 \mathrm{wt} \% \\
\text { loss }\end{array}$ & \\
\hline 4 & 95 & 305 & 401 & 568 & 46 \\
\hline 5 & 94 & 257 & 398 & 497 & 47 \\
\hline 6 & 90 & 278 & 410 & 465 & 38 \\
\hline
\end{tabular}

ence was recorded. Figure 5 shows the angular dependence of SHG signal in a poled polymer 5 . The SHG values were compared with those obtained from a Y-cut quartz plate. To calculate the $d_{31}$ and $d_{33}$ values, both s-polarized and $\rho$ polarized IR laser were directed to the samples and recorded. SHG coefficients $\left(d_{33}\right)$ were derived from the analysis of measured Maker-fringes with the Pascal fitting program according to the literature procedure. ${ }^{18}$ Nonlinear optical properties of polymers 4-6 are summarized in Table 3. The values of $a_{33}$ and $d_{31}$ for polymer 5 were $(1.38 \pm 0.10) \times 10^{-9}$ and $(0.51 \pm 0.04) \times 10^{-9}$ esu. which were similar with those of polymer $4 .^{19}$ According to our experimental experience, the $d_{33}$ and $d_{31}$ values of polymers +-6 are somewhat smaller than those of the polyesters containing 2.3-dioxynitrostilbenyl group. ${ }^{15}$ Since the second hamonic wavelength is at $532 \mathrm{~nm}$, which is not in the absorptive region of the resulting polyesters. there was not resonant contribution to this $d_{33}$ value. In the isotropic model. the ratio of $d_{33} / d_{31}$ is predicted to be about 3 . Our $d_{32} / d_{31}$ value of 2.7 is in good 


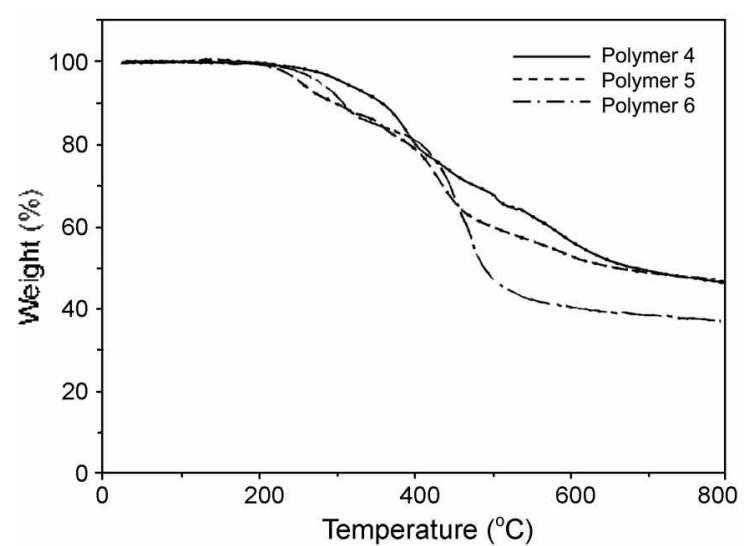

Figure 2. TGA themograms of polymers 4-6 at a heatung rate of $10^{\circ} \mathrm{C} / \mathrm{min}$ under nitrogen.

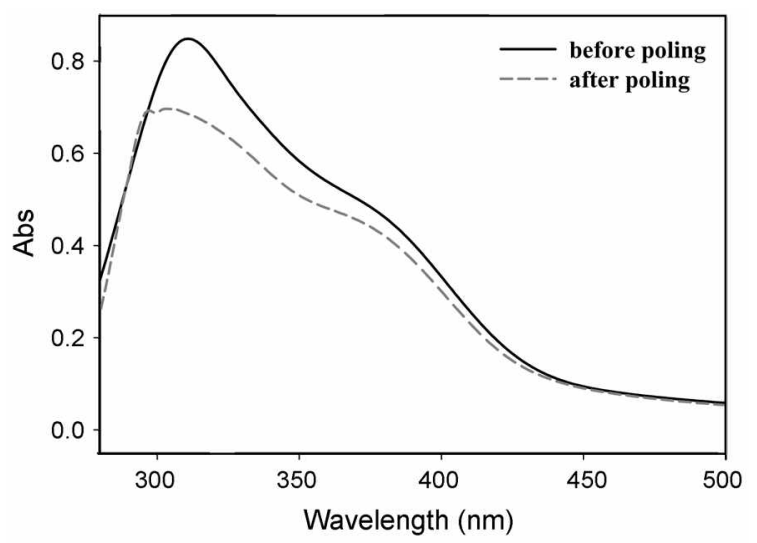

Figure 3. UV-Vis absorption spectra of a film of polymer 5 before and after poling.

agreement with the predicted value.

To evaluate the high-temperature stability of the polymers. we studied the temporal stability of the SHG signal. In Figure 6. we present the dynamic thermal stability study of the NLO activity of the film 5 . To investigate the real time NLO decay of the SHG signal of the poled polymer films as a function of temperature in situ SHG measurements were performed at a heating rate of $3{ }^{\circ} \mathrm{C} / \mathrm{min}$ from $30^{\circ} \mathrm{C}$ to 150 ${ }^{\circ} \mathrm{C}$. The polymer film exhibited a thermal stability up to $5^{\circ} \mathrm{C}$ higher than $T_{y}$ and no significant SHG decay was observed below $100^{\circ} \mathrm{C}$ for polymer 5 . In general. side chain NLO polymers lose thermal stability of dipole aligmment below
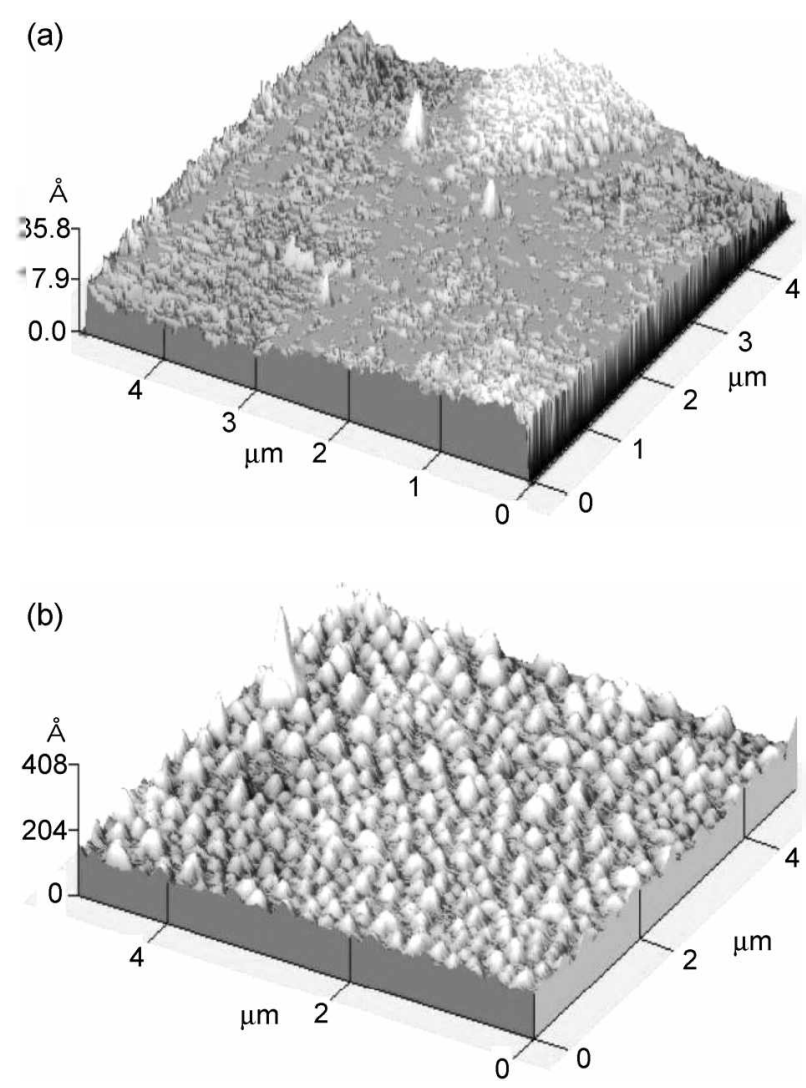

Figure 4. AFM images of spin-coated film of polymer 5: (a) betore corona-poling; (b) after corona-poling.

$T_{g}$. Stabilization of dipole aligument is a characteristic of main chain NLO polymers. The ligh thennal stability of second harmonic generation of polymers is due to the stabilization of dipole aligument of NLO chromophore, which stems from the partial main chain character of the polymer structure. Thus. we obtained a new type of NLO polyester having both of the merits of main chain- and sidechain NLO polymers: stabilization of dipole alignment and good solubility:

\section{Conclusions}

Novel T-type NLO polyesters (4-6) with pendant NLO chromophores. which are parts of the polymer backbones. were prepared and characterized. Polymers 4-6 are soluble in common organic solvents. The resulting polymers 4-6

Table 3. Nonlinear Optical Properties of Polymers 4-6

\begin{tabular}{|c|c|c|c|c|c|c|}
\hline Polymer & $\lambda_{\max }{ }^{\sigma}(\mathrm{nm})$ & $d_{33^{b}}^{b}$ (esu) & $\Phi^{r}$ & $d_{31}{ }^{\prime}$ (esu) & film thickness $s^{\prime}$ ( $\left./ a n 1\right)$ & $n$ \\
\hline 4 & 376 & $(1.42 \pm 0.09) \times 10^{-4}$ & 0.19 & $(0.52 \pm 0.03) \times 10^{-9}$ & 0.47 & $\begin{array}{l}\mathrm{n}_{1}=1.58 \\
\mathrm{n}_{2}=1.66\end{array}$ \\
\hline 5 & 375 & $(1.38 \pm 0.10) \times 10^{-4}$ & 0.18 & $(0.51 \pm 0.04) \times 10^{-9}$ & 0.51 & $\begin{array}{l}\mathrm{n}_{1}=1.63 \\
\mathrm{n}_{2}=1.73\end{array}$ \\
\hline 6 & 376 & $(1.16 \pm 0.08) \times 10^{-8}$ & 0.51 & $(0.43 \pm 0.03) \times 10^{-9}$ & 0.48 & $\begin{array}{l}n_{1}=1.61 \\
n_{2}=1.69\end{array}$ \\
\hline
\end{tabular}

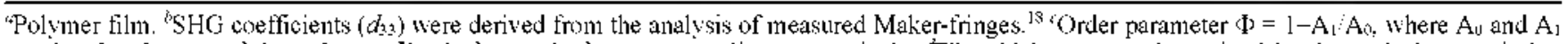
are the absorbances of the polymer film before and after corona poling. respectively. "Film thickness was determined by the optical transmission technique. ${ }^{1 ?}$ 


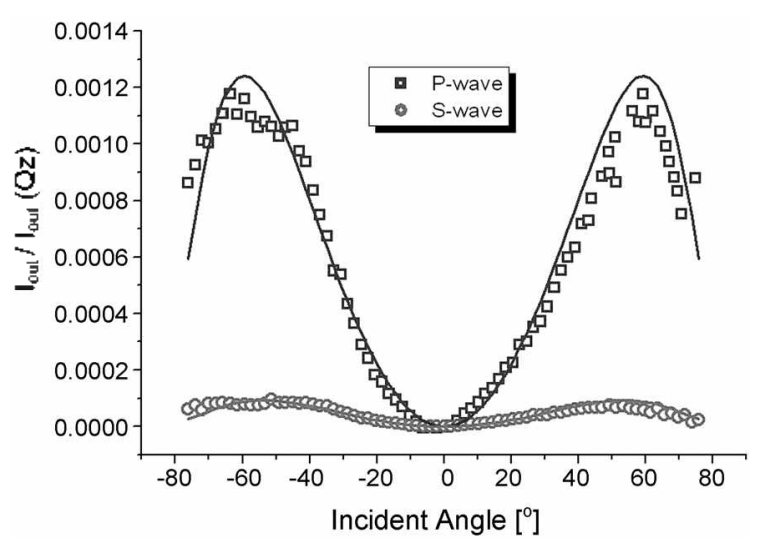

Figure 5. Angular dependence of SHG signal in a poled filn of polymer 5 .

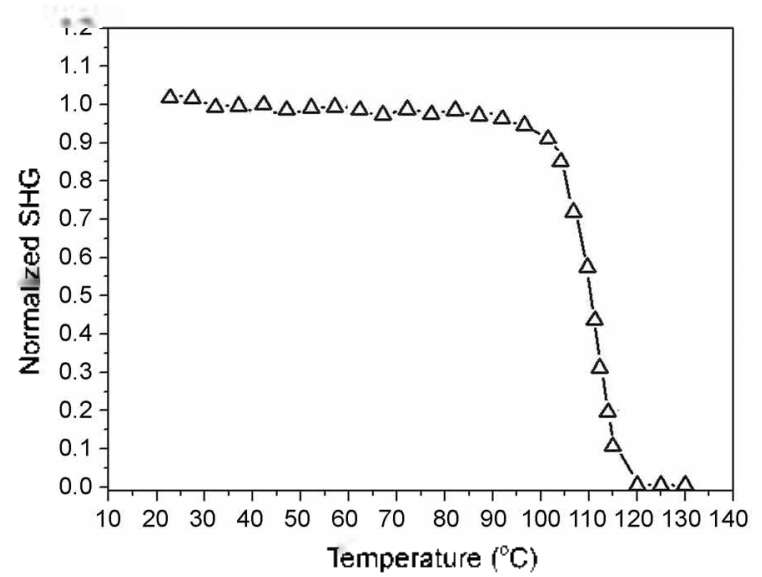

Figure 6. Nomalized $\mathrm{SHG}$ signal of polymer 5 as a function of temperature at a heating rate of $3^{\circ} \mathrm{C} / 117 n$.

showed a thermal stability up to $260^{\circ} \mathrm{C}$ with $T_{g}$ values in the range $90-95^{\circ} \mathrm{C}$. The SHG coefficients $\left(d_{33}\right)$ of poled polymer films were around $1.42 \times 10^{-19}$ esu. Poled polymer films exhibited a thermal stability of SHG up to $5^{\circ} \mathrm{C}$ higher than $T_{g}$ due to the partial main-chain character of the polymer structure. which is acceptable for NLO device applications.

\section{Experimental Section}

Materials. The reagent grade chemicals were purchased from Aldrich and purified by either distillation or recrystallization before use. 4-Nitrophenylacetic acid. 2,5-dihydroxybenzaldehyde. 2-chloroethyl vinyl ether. and sebacoyl chloride (SCC) were used as received. Terephthaloyl chloride (TPC) was purified by sublimation under vacuum. Adipoyl chloride (APC) was purified by distillation under reduced pressure. Piperidine was treated with potassium hydroxide and then distilled over barium oxide to remove trace amounts of water. $N, N$-Dimethylformamide (DMF) was purified by drying with anhydrous calcium sulfate. followed by distillation under reduced pressure.

Measurements. IR spectra were taken on a Shimadzu FT IR-8201PC infrared spectrophotometer. ${ }^{1} \mathrm{H}$ NMR spectra were obtained on a varian $300 \mathrm{MHz}$ NMR spectrometer.
UV-VIS absorption spectra were measured on a Shimadzu UV-3100S spectrophotometer. Elemental analyses were performed using a Perkin-Elmer $2400 \mathrm{CHN}$ elemental analyzer. The glass transition temperatures $\left(T_{y}\right)$ were measured on a TA 2920 differential scanning calorimeter in a nitrogen atmosphere. DuPont $95 \mathrm{l}$ thermogravimetric analyzer with a heating rate of $10{ }^{\circ} \mathrm{C} / \mathrm{min}$ up to $800^{\circ} \mathrm{C}$ was used for the themal degradation study of polymers under nitrogen. The number average molecular weight $\left(M_{n}\right)$ and weight average molecular weight $\left(M_{*}\right)$ of the polymers were estimated by gel permeation cluromatograply (GPC) (colunus Styragel HR5E4E; solvent THF). Atomic force microscopy (AFM) images were recorded with a Park Science Instrument Autoprobe $C$. operated in a contact mode, which measures topography. Melting points were measured with a Buchi 530 melting point apparatus and are corrected. Viscosity values were obtained by using a Cannon-Fenske viscometer.

Film Preparation and SHG Measurement. The polymer film was prepared from a $10 \mathrm{wt} \%$ by weight polymer solution in DMF deposited on an indiun-tin oxide (ITO) covered glass. Prior to film casting. the polymer solution was filtered through $0.45 \mu \mathrm{m}$ Teflon ${ }^{\mathbb{E}}$ membrane filter. The film was spin cast at room temperature in the range $1000-1200$ $\mathrm{rpm}$. The films were dried for $12 \mathrm{~h}$ under vacuum at $60^{\circ} \mathrm{C}$ The alignment of the NLO-cluromophore of the polymers was carried out by corona poling method. The poling was perfonmed in a wire-to plane geometry under in situ conditions. The discharging wire to plane distance was $10 \mathrm{~mm}$. As the temperature was raised gradually to $5-10^{\circ} \mathrm{C}$ higher than $T_{3} .6 .5 \mathrm{kV}$ of corona voltage was applied and kept that temperature for $30 \mathrm{~min}$. The films were cooled to room temperature in the presence of the electric field. Finally. the electric field was removed. The refractive index of the sample was measured by the optical transmission technique. ${ }^{17}$ Second harmonic generation measurement was carried out one day after poling. A continuum PY61 mode-locked $\mathrm{Nd}$ :YAG laser $(\lambda=1064 \mathrm{~nm})$ with pulse width of $40 \mathrm{ps}$ and repetition rate of $10 \mathrm{~Hz}$ was used as the fundamental light source and Y-cut quartz was used as reference. A beam splitter and a photodiode were used to compensate for the intensity fluctuations of the fundamental beam (1064 nm). The polarity of the fundamental laser beam was adjusted using a half-wave plate before it hit the sample. The electric field vector of the incident beam was either parallel ( $p$ polarization) or perpendicular ( $s$-polarization) to the plane of incidence. Only the $p$-polarized SH bean was made to enter a photomultiplier tube (PMT) by using a prism and a $\mathrm{SH}$ pass filter. An analyzer was used to confim the polarization direction of the SH signal. A poled polymer film was mounted on the rotator coupled to a step motor. The output signals from the photodiode and PMT were detected as a function of the incident angle. A 3-1mm-thick Y-cut quartz crystal (a piece of quartz plate whose plane is perpendicular to the crystalline $y$-axis and the thickness of the plate is 3 $\mathrm{mm}$. and $\mathrm{d}_{11}=0.3 \mathrm{pm} / \mathrm{V}$ ) was used as a reference for determining the relative intensities of the SH signals generated from the samples. The Maker Fringe pattem was obtained 
by measuring the $\mathrm{SHG}$ signal at $0.5^{\circ}$ intervals using a rotation stage. SHG coefficients $\left(d_{33}\right)$ were derived from the analysis of measured Maker-fringes. ${ }^{\text {is }}$

Preparation of 2,5-Dihydroxy-t'-nitrostilbene 1. Compound 1 was prepared by a known method from 2,5-dihydroxybenzaldehyde and 4-nitrophenylacetic acid, and recrystallized from $80 \%$ aqueous ethanol. ${ }^{~} \mathrm{H}$ NMR (acetone$\left.d_{6}\right) \delta 2.79(\mathrm{~s}, 2 \mathrm{H},-\mathrm{OH}) .7 \cdot 12-7.35$ (n. $4 \mathrm{H}$. aromatic), 8.06$8.15(\mathrm{~d}, 2 \mathrm{H}$, aromatic). 8.23-8.37 (t, $3 \mathrm{H}$. aromatic). IR (KBr) 3408 (s, O-H). 3032 (w. $=\mathrm{C}-\mathrm{H}), 2876$ (w. C-H), 1574 (vs. $\mathrm{C}=\mathrm{C}), 1510,1348(\mathrm{vs}, \mathrm{N}=\mathrm{O}) \mathrm{cm}^{-1}$.

Preparation of 2,5-Di-(2'-vinyloxyethoxy)- $t^{\prime}$-nitrostilbene 2. 2.5-Dihydroxy-4'-nitrostilbene $(7.71 \mathrm{~g} .0 .03 \mathrm{~mol})$. anhydrous potassium carbonate $(24.9 \mathrm{~g} .0 .18 \mathrm{~mol})$, and 2 chloroethyl vinyl ether $(8.52 \mathrm{~g}, 0.08 \mathrm{~mol})$ were dissolved in $100 \mathrm{~mL}$ of dry DMF under nitrogen. The mixture was refluxed in an oil bath kept at $80^{\circ} \mathrm{C}$ for $15 \mathrm{~h}$ under nitrogen. The resulting solution was cooled to room temperature. diluted with $200 \mathrm{~mL}$ of water. stirred. filtered. and the obtained product was washed with $100 \mathrm{~mL}$ of water. Thus obtained product was recrystallized from ethanol to give $10.25 \mathrm{~g}(86 \%$ yield $)$ of $2 . \mathrm{Mp}=146-148{ }^{\circ} \mathrm{C} .{ }^{1} \mathrm{H}$ NMR (DMSO- $d_{6}$ ) $\delta 3.96-4.07$ (d, $6 \mathrm{H}, \mathrm{CH}_{2}=.-\mathrm{O}-\mathrm{CH}_{2}=\mathrm{CH}_{2}-\mathrm{O}-$ ). $4.18-4.30$ (d. $6 \mathrm{H} . \mathrm{CH}_{2}=.-\mathrm{O}-\mathrm{CH}_{2}=\mathrm{CH}_{2}-\mathrm{O}-$ ). $6.52-6.63$ (q. $2 \mathrm{H}$. $2=\mathrm{CH}-\mathrm{O}-$ ). $7.26-7.47$ (m, $4 \mathrm{H}$. aromatic). $7.95-8.05$ (d, $2 \mathrm{H}$. aromatic), 8.26-8.42 (t. 3H, aromatic). IR (KBr) 3059 (w. $=\mathrm{C}-\mathrm{H}$ ), 2953 (n. C-H). 1572 (s. $\mathrm{C}=\mathrm{C}$ ). 1512.1350 (vs. $\mathrm{N}=\mathrm{O}$ ) $\mathrm{cm}^{-1}$. Anal. Calcd for $\mathrm{C}_{2} \mathrm{H}_{23} \mathrm{NO}_{6}$ : C. 66.49: $\mathrm{H}, 5.83$ : N. 3.52. Found: C. $66.60 ;$ H. 5.89: N. 3.46.

Preparation of 2,5-Di-(2'-hydroxyethoxy)-t'-nitrostilbene 3. Aqueous hydrochloric acid (1.5 M. $30 \mathrm{~mL}$ ) was slowly added to a solution of 2.5-di-(2'-vinyloxyethoxy)-4'nitrostilbene (2) $(9.93 \mathrm{~g}, 0.025 \mathrm{~mol})$ in $60 \mathrm{~mL}$ of dry DMF with stirring under nitrogen at $0^{\circ} \mathrm{C}$. The nixture was stirred at $80^{\circ} \mathrm{C}$ for $8 \mathrm{~h}$ under nitrogen. The resulting solution was extracted with diethyl ether $(80 \mathrm{~mL})$ three times. The organic layer was washed successively with saturated sodiun chloride. sodium hyddrogen carbonate and water. followed by drying with anhyddrous magnesium sulfate. Rotary evaporation of diethyl ether gave crude product. The obtained pale yellow product was recrystallized from ethyl acetate to give $7.41 \mathrm{~g}$ (vield $86 \%$ ) of 3 (Scheme 1) $\mathrm{Mp}=168-170{ }^{\circ} \mathrm{C} .{ }^{\mathrm{l}} \mathrm{H}$ NMR (DMSO- $\left.c_{6}\right) \delta 3.62-3.78\left(\mathrm{~m} .+\mathrm{H},-\mathrm{O}-\mathrm{CH}_{2}-\mathrm{CH}_{2}-\mathrm{O}-\right.$ ). $3.92-$ $4.08\left(\mathrm{t}, 4 \mathrm{H} .-\mathrm{O}-\mathrm{CH}_{2}-\mathrm{CH}_{2}-\mathrm{O}-\right), 7.20-7.46(\mathrm{~m}, 4 \mathrm{H}$. aromatic). $7.91-8.02$ (d, $2 \mathrm{H}$, aromatic), $8.20-8.43$ (t. $3 \mathrm{H}$. aromatic). IR (KBr) 3420 (s. O-H), 2936, 2870 (m, C-H), 1585 (s. C=C). 1518. 1344 (vs. $\mathrm{N}=\mathrm{O}$ ) $\mathrm{cm}^{-1}$. Anal. Calcd for $\mathrm{C}_{18} \mathrm{H}_{19} \mathrm{NO}_{6} \mathrm{C}$. $62.60 ; \mathrm{H}, 5.54 ;$ N. 4.06. Found: C. 62.68: H, 5.63; N. 4.12.

Synthesis of Polyesters 4-6. A representative polycondensation procedure (the case of 4) was as follows: Terephthaloyl chloride ( $2.03 \mathrm{~g} .0 .01 \mathrm{~mol})$ and diol $3(3.45 \mathrm{~g}$. $0.01 \mathrm{~mol}$ ) were dissolved in $30 \mathrm{~mL}$ of anhydrous pyridine under nitrogen. The resulting solution was refluxed in an oil bath kept at $80^{\circ} \mathrm{C}$ under a nitrogen atmosphere. After heating $10 \mathrm{~h}$ with stirring the resulting polymerization solution was poured into $400 \mathrm{~mL}$ of methanol. The precipitated polymer was collected and reprecipitated from
DMSO into methanol. The polymer was further purified by extraction in a Soxhlet extractor with diethyl ether and dried under vacuum. yielding $4.37 \mathrm{~g}$ (92\% yield) of polymer 4 . Inherent viscosity $\left(\eta_{\mathrm{nd}}\right)=0.30 \mathrm{dL} / \mathrm{g}(\mathrm{c}=0.5 \mathrm{~g} / \mathrm{dL}$ in DMSO at $25^{\circ} \mathrm{C}$ ). ${ }^{1} \mathrm{H}$ NMR (DMSO- $\left.d_{6}\right) \delta 4.36-4.45$ (s. $4 \mathrm{H}, 2-\mathrm{CH}_{2}-$ O-), 4.63-4.69 (s, 4H, 2 Ph-O-CHs $), 7.27-7.45(\mathrm{~m}, 3 \mathrm{H}$, aromatic). $7.95-8.13$ (m. $6 \mathrm{H}$, aromatic). $8.27-8.39$ (m. $4 \mathrm{H}$, aromatic). IR (KBr) 2941. 2883 (C-H. w). 1722 (vs. C=O). 1572 (s. $\mathrm{C}=\mathrm{C}$ ), 1520.1350 (s, $\mathrm{N}=\mathrm{O}$ ) $\mathrm{cm}^{-1}$. Anal. Calcd for $\left(\mathrm{C}_{26} \mathrm{H}_{21} \mathrm{NO}_{8}\right)_{3} ; \mathrm{C} .65 .68 ; \mathrm{H}, 4.45 ;$ N. 2.95 . Found: C. 65.78: H, 4.53: N. 3.04. Polymer 5: $\eta_{\text {unh }}=0.30 \mathrm{dL} / \mathrm{g}(\mathrm{c}=0.5 \mathrm{~g} / \mathrm{dL}$ in DMSO at $25^{\circ} \mathrm{C}$ ). ${ }^{1} \mathrm{H}$ NMR (DMSO- $\left.d_{6}\right) \delta 1.41-1.57$ (s, $4 \mathrm{H}$, $-\mathrm{CH}_{2}-\mathrm{CH}_{2}-$ ), 2.15-2.36 (d, 4H. $2-\mathrm{CH}_{2}-\mathrm{CO}-$ ), 4.15-4.43 (d, $8 \mathrm{H} .2-\mathrm{O}-\mathrm{CH}_{2}-\mathrm{CH}_{2}-\mathrm{O}-$ ). $7.20-7.44$ (m. $4 \mathrm{H}$, aromatic), 7.928.03 (t, 2H, aromatic). 8.25-8.39 (m. 3H, aromatic). IR (KBr) 2953, 2885 (C.H. m). 1722 (vs. C=O). 1572 (s, C=C). 1520. 1350 (vs. $\mathrm{N}=\mathrm{O}$ ) $\mathrm{cm}^{-1}$. Anal. Calcd for $\left(\mathrm{C}_{24} \mathrm{H}_{25} \mathrm{NO}_{8}\right)_{n}$ : C. $63.29 ;$ H. $5.53 ;$ N, 3.08 . Found: C, 63.36; H. 5.62; N, 3.15. Polymer 6: $\eta_{\text {unh }}=0.32 \mathrm{dL} / \mathrm{g}(\mathrm{c}=0.5 \mathrm{~g} / \mathrm{dL}$ in DMSO at $25^{\circ} \mathrm{C}$ ). ${ }^{1} \mathrm{H}$ NMR (DMSO- $\left.l_{6}\right) \delta 1.03-1.27\left(\mathrm{~s} .8 \mathrm{H} .-\left(\mathrm{CH}_{2}\right)_{4}-\right)_{-}$, $1.33-1.52$ (s. $4 \mathrm{H}, 2-\left(\mathrm{CH}_{2}\right)-$ ), 2.09-2.32 (m. $4 \mathrm{H} .2-\mathrm{CH}_{2}-\mathrm{CO}$ ), $4.18-4.39$ (d, 8H, $\left.2-\mathrm{O}-\mathrm{CH}_{2}-\mathrm{CH}_{2}-\mathrm{O}-\right)$. 7.23-7.44 (m, $4 \mathrm{H}$, aromatic). $7.93-8.03$ (t. $2 \mathrm{H}$, aromatic), $8.27-8.38(\mathrm{~m}, 3 \mathrm{H}$, aromatic). IR (KBr) 2930. 2860 (C.H. s), 1728 (vs. C=O). 1572 (s. $\mathrm{C}=\mathrm{C}$ ). $1520.1350\left(\mathrm{vs}, \mathrm{N}=\mathrm{O}\right.$ ) $\mathrm{cm}^{-1}$. Anal. Calcd for $\left(\mathrm{C}_{26} \mathrm{H}_{29} \mathrm{NO}_{8}\right)_{3} ; \mathrm{C} .64 .58 ; \mathrm{H}, 6.05 ;$ N. 2.90 . Found: C, 64.66: H, 6.14; N. 2.98 .

Acknowledgement. This work was supported by the 2007 Inje Univerșity research grant.

\section{References}

1. Marks. I. T.: Ratner. M. A. Angew: Chent. Int Ed Engt 1995. 3t. 155.

2. Cho. M. I.: Kim. J. Y.: Kim. J. H.: Lee. S. H.: Dalton. L. R.: Choi. D. H. Bull Kowan Chem Soc. 2005. 26.77.

3. Lee. C. Park, S.-K: Yang M.; Lee, N.-S.; Kim. N. J. Bull. Korean Chem. Soc. 2007. 28. 447.

4. Han1. K. S.: Park. S. K.: Shim. S. Y.: Tahn1g. W. S.: Kim. N. T. BulI Korean Chem. Soc. 1998. 19, 1165

5. Han. K. S.; Park, S. K.: Shim. S. Y.: Lee, Y. S.: Jahng. W. S.: Kim. N. J. Bull. Korean Chem. Soc. 1998. 19. 1168.

6. Cho. B. R.: Kim. Y. H.: Son1. K. W.: Khalil. C.: Kim. Y. H.: Teon. S.-T. Bull. Korew Chent Soc. 2012. 23.1253.

7. Moon. J. R.: Kim. B. S.: Kim, J.-H. Bull. Koram Chem. Soc 2006. 27,981

8. Kim. M. H.: Jin. J.-I; Lee, C. J.: Kim. N. J.; Park, C. H. Bull Korem Chem. Soc. 2002. 23. 964

9. Lee. T.-H.: Lee. K.-S. Bull. Korem Chem. Soc. 2000. 21.847.

10. Lee, S.-H.: Kim. Y.-K.: Won. Y.-H. Macmomolectles $1999,32,342$.

11. Renate. D.: Walter. M. F. F, Dietmar. K.: Hans, J. Dies and Pigntents 1997.34. 13.

12. Ambrosanio. P.: Centore. R.: Concilio. S.: Panutuzi. B.: Sirigu. A.: Tirelli. N. Polvmer 1999. 40. 4923

13. Lee. J.-Y.: Jung. W.-T.: Lee. W.-J. Polym Iht 2006, 55. 248.

14. Lee. J.-Y: Kim, J.-H.: Won, D.-S.; Jang, H.-N. Bull. Kowan Chent Soc 2007.28 .1433$.

15. Kim. T.-H.: Lee. J.-Y.: Won. D.-S.: Rhee. B. K. Macronol. Res: 2007. 15.506

16. Cullinane, N. M. J. Chem. Soc. 1923. 123. 2053.

17. Cisneros, J. I. Appl. Opt. 1998. 37. 5262.

18. Herman. W. N.: Hayden. L. M. J. Opt. Soc. Ant B 1995. 12. 416

19. Lee. J.-Y.: Kim. T.H.: Jung. W.-T. Bull. Korem Chem. Soc. 2007. 28. 329 . 